\title{
Social Support and Personal Resilience of Government Employees
}

\author{
Rinante L. Genuba, Marife E. Abaya, Annabelle R. Dafielmoto, Merlinda T. Espirituoso, Lyn Marie \\ C. Centeno, Dr. Alberto S. Bandiola
}

University of Mindanao, Davao, Philippines

\begin{abstract}
The study primarily aims to determine which domain of social support significantly influences the personal resilience of government employees. The study utilized a descriptive correlational design and employed a survey method to attain the research objectives. The selected respondents were the 210 government employees who were selected through a stratified random sampling technique. The researchers made use of the pilot-tested and enhanced adapted questionnaires. The statistical tools used were mean pearson $r$ and regression. As reflected on the results, social support and personal resilience of government employees obtained different mean scores but both belong to high descriptive levels. Further, it was found out that there is a significant relationship between social support and the personal resilience of government employees. Furthermore, it was found that social support significantly influences personal resilience having three out of four domains contributed to its significant influence. Lastly, it was the emotional support that emerged as the best predictor in this study.
\end{abstract}

Keywords: public administration, social support, personal resilience, emotional support, Philippines

\section{Introduction}

Individual resilience involves behaviors, thoughts, and actions that promote personal well-being and mental health. People can develop the ability to withstand, adapt to, and recover from stress and adversity and maintain or return to a state of mental health well-being by using effective coping strategies. People develop resilience by learning better skills and strategies for managing stress and better ways of thinking about life's challenges.

To be resilient one must tap personal strengths and the support of family, friends, neighbors, and/or faith communities (SAMHSA, 2020). The COVID-19 pandemic has seen to have serious impact on individuals throughout the world (Brooks, et.al, 2020; Xiao, et.al, 2020), but its impact is greater on adolescents than adults because they are more vulnerable to the negative effects of stress (Chassin, et.al, 2003). Further, its associated social and economic stressors undermine adolescent's development and well-being (Bartlett \& Vivrette, 2020) including physical, psychosocial, cognitive, and mental health, and on family relationships (Cluver, et.al, 2020). Since people respond to stress and adversity like that from the COVID-19 pandemic differently, hence, resilience can help get through and overcome hardship (Center on Developing Child, 2020). Studies suggest that exposure and experience with challenges or adversity are important for developing resilience processes and growing youths' capacity and skills for handling stressful experiences (Masten, 2015), and developing resilience in adolescents will help them in meeting the challenges and responsibilities of adulthood (Werner, 1995) and contribute to nation building.

Theoretical perspectives and empirical research suggest that social support in some degree has to do with resilience. Social support acts as a shield against the negative effects of stressful life events and, thus, negative effects on mental health (Colarossi \& Eccles, 2003; Jackson, 1992). Hence, the level and degree of social support affects the level of resilience as a protective factor in individuals (Cicchetti \& Toth, 1998). On 
the other hand, spirituality promotes healthy development in adolescents, enhances the ability to cope, and leads to positive outcomes in mental health and psychological well-being (Kim \& Esquivel, 2011).

Considering the above context, the researcher decided to propose a study with the social support as independent variable and personal resilience during a pandemic as dependent variable. No study has looked at the effects of a pandemic on adolescent health and little research has been done on the characteristics of vulnerable groups and factors that promote resilience (Rome, Dinardo, \& Issac, 2020; Tso,et.al, 2020). Further, most current measures of resilience have limited focus, only addressing individual characteristics (Connor \& Davidson, 2003) (Jew, Green, \& Kroger, 1999; Wagnild \& Young, 1993), thus it is vital to examine resilience more broadly. Hence, this study will respond to the prevailing issues on limited studies of adolescents' personal resilience, especially during a pandemic. Also, this will be the first study on adolescent's personal resilience during a pandemic.

\section{Research Objectives}

This study aims to determine the domains of social support that significantly influence the personal resilience of government employees. Specifically, it dealt with the following objectives: To assess the level of social support in terms of emotional support, instrumental support, need for support and support seeking. To ascertain the level of personal resilience in terms of novelty seeking, emotional regulation and positive future orientation. To determine the significant relationship between social support and personal resilience of government employees. Lastly, to determine the domain of social support that significantly influence personal resilience of government employees.

\section{Hypothesis}

The following hypotheses were developed based on the above goals; there is no significant relationship between social support and personal resilience and social support does not significantly influence personal resilience.

\section{Literature Review \\ Social Support}

The social support theory proposes two major models, the main effect model and the buffering effect model to explain the association between social support and well-being (Armstrong, Bernie-Lefcovitch \& Ungar, 2005). The first, known as the main effect model of social support, is defined through social integration and has a general positive context and beneficial effect on well-being regardless of whether or not there is an actual stressful experience (Dumont \& Provost, 1999). Secondly, the buffering model hypothesizes that social support protects individuals against the negative effects of stressful events (Helsen, Vollebergh \& Meeus, 2000; Rowlinson \& Felner, 1988).

Based on the theory that not all social support is the same Colarossi and Eccles (2003) examined the effects of parent, teacher, and peer social support on the mental health of 217 adolescents. Support received from friends and teachers significantly and positively affected self-esteem. An important part of adolescence is identity formation and, in many ways, then on family sources are important for self-concept and a sense of worthiness outside parental support. Of all supports examined by Colarossi and Eccles, parental support was found to have the largest effect on levels of depression. It is suggested that this is due to the longer-term nature of the relationship on depressive systems (Colarossi \& Eccles, 2003). It has been found that parental support may have a cumulative effect over time because of the relatively stable and long-standing parentchild relationship, which has notable effects on levels of depression (Garnefski \& Diekstra, 1996). An individual's perception of support affects mental health outcomes by increasing beliefs of acceptance, selfworth and connectedness to others (Colarossi \& Eccles, 2003).

In one study of social support, 297 adolescents were classified into 3 groups: well-adjusted, resilient, and vulnerable based on crossing scores of depressive symptoms and frequency of daily hassles (Dumont \& Provost, 1999). It was evident from the results of this study that resilient adolescents were better able to solve problems than those in the other groups. However, an important finding from this research was that social support did not significantly differentiate the groups of adolescents. The authors acknowledged that this was a very surprising result considering the literature (Colarossi \& Eccles, 2003; Horton \& Wallander, 2001) has placed so much emphasis on the buffering effects of social support on mental health. 
Emotional Support is the first indicator of social support. Social support is often further broken into different types- for instance instrumental support and emotional support - as often people have preferences for different types of aid depending on the circumstances (Reblin \& Uchino, 2008). Sarafino (1998) points out that emotional support is the feeling of affection, friendship, care, attention, love and confidence that others demonstrate to the individual and his sense of comfort and belonging. Catrona \& Russell (1990) defined emotional support as the need for help and security in stressful times, resulting in an individual sense of caring for others.

The concept of emotional support includes a wide range of behaviors such as empathy, confrontation, compassionate participation, caring, encouragement toward others, love that appear in caring and attention, valued feeling, and dependable bonds of friendship (Gregory, et al., 1996; Campbell \& Wright, 2002). Gregory, Sarson, and Sarason (1996) note that potential emotional support providers include family, friends, co-workers, colleagues, and experts such as counselors and clergy. The emotional characteristics of personal life of the human being include communication, attention, moral guidance and trust, thus providing an opportunity to vent emotions (Cohen, 2004; Cohen \& Wills, 1985). Receiving emotional support helps individuals to cope with problems, anxiety, and disappointments of hope and pain in their lives, but if left unchecked or treated, it will have serious negative effects that can affect the physical, psychological and emotional health of the individual (Burleson, 1990). Adolescences, in particular, requires providing emotional support to ensure arriving to a good level of psychological growth, good human interaction and close personal relationships such as friends, family, or emotional relationships (Burleson, 2003). The importance of emotional support emanates from the fact that individuals who receive more emotional support or realize that emotional support is available are happier, healthier, and able to cope with the problems and troubles of life (Catrona \& Russell, 1990; Pierce, Sarason \& Sarason, 1990).

Instrumental support is the second indicator of social support. Instrumental support, the degree to which an individual receives assistance in the completion of daily life tasks, is an important but often neglected component of social support (Malecki \& Demaray, 2003). Instrumental social support refers to overt behaviors that directly facilitate adolescents' involvement (Heaney \& Israel, 2002). Instrumental support can be conceptualized as the provision of resources which can entail financial support, material resources, or support in performing tasks like child care or household chores (Cohen \& Wills, 1985). Instrumental, nonfinancial support can come in the form of child care, respite care, transportation, home modifications, training, crisis intervention, faith-based services, and assistance with the transition to adult group homes (Johnson \& Kastner, 2005). Instrumental support includes feelings of warmth and closeness with parents (Russek and Schwartz, 1997) and parental academic involvement (Westerlund et al., 2013). Additionally, support from parents provided to adult children has been shown to be greater for children who are considered by their parents to have more problems (Fingerman, Miller, Birditt, \& Zaritt, 2009).

\section{Personal Resilience}

Research into resilience encompasses many areas including individuals' abilities of recovering to normal functioning during different stages of development after adversity (Alvord \& Grados, 2005). This was demonstrated through a study of Romanian children that had experienced severe deprivation during infancy and were later assessed to show significant improvements both physically and cognitively after being adopted into nurturing homes (Rutter \& The English and Romanian Adoptees (ERA) Study Team, 1998). The study examined a sample of 111 Romanian orphans that came to the United Kingdom (U.K.) for adoption before the age of 2 years. The extent of developmental deficit was assessed at time of entry to the U.K. and most children were severely developmentally impaired. Further physical and cognitive assessments were carried on the children at 4 years of age to examine the developmental catch-up. For those children adopted before 6 months of age both physical growth and cognitive levels were almost complete. The developmental catch-up was also very impressive, however, not complete for children adopted after 6 months of age (Rutter et al., 1998). Masten (2001) claims such a recovery-to-normal trajectory of development is evidence of resilience.

Masten (2001) suggested that resilience stems from the healthy operation of basic human adaptational systems. Although, Miller (2002) acknowledges that consensus has not been reached in defining or describing what is meant by the term resilience. The outcomes or consequences of resilience that have been recognized are effective coping, mastery, and positive adaptation (Earvolino-Ramirez, 2007). Another phenomenon of resilience is that of the ability of some individuals to actively create experiences that foster 
competence (Armstrong, et al., 2005). In his study of students with disabilities, Miller (2002) aimed to identify several elements of resilience. A predominant difference between the resilient and non-resilient students was the ability of resilient students to identify their experiences of success and more importantly to take the deliberate steps that were necessary to attaining success (Miller, 2002). Resilience is therefore linked to self-efficacy in that both require the process of becoming aware of one's strengths (Lightsey, 2006). From a developmental perspective, a common theme in theoretical frameworks for adolescent resilience is the consideration of the individual's developmental level and functioning, the multiple levels of influence on developmental pathways, and the connection between the risk and protective factors and the individual's adjustment (Armstrong, Bernie, Lefcovitch \& Ungar 2005). Resilience in adolescence occurs through nominal adaptive processes, including cognitive development, behaviour regulation and interactions with the environment (Masten, 2001).

Novelty Seeking is the first indicator of resilience. It measures an emotional drive to activate behavior because of curiosity to explore and to enjoy what is new and complex (Eley, 2006). Novelty Seeking influences choice preference and enhances exploration during decision making (Wittmann, et.al, 2008). Some personality traits, including novelty seeking, are good predictors of vulnerability to stress-related mood disorders (Duclot \& Kabbaj, 2003). Several clinical reports indicate that personality traits, including novelty seeking, can be used to predict further vulnerability to mood disorders (Josefsson et al., 2011; Black et al., 2012; Wu et al., 2012). Recent evidence suggests that early exposure to mild stress promotes the development of novelty seeking behavior (Parker, et.al, 2007). In many circumstances, humans and other animals are naturally inquisitive and have a characteristic tendency to explore novel and unfamiliar stimuli and environments (Wittmann, et.al, 2008). Cloninger proposed Novelty Seeking (NS) as a personality trait that refers to the tendency to be intensely exhilarated or excited in response to novel stimuli Cloninger, 1991). Human neuroimaging studies have reported that NS is associated with the activation elicited by emotional stimuli in the medial frontal gyrus (Bermpohl, F. et al.), and other personality traits such as harm avoidance (Naghavi, 2009).

Emotional regulation is the second indicator of resilience. It has been defined as "all the extrinsic and intrinsic processes responsible for monitoring, evaluating and modifying emotional reactions, especially their intensive and temporal features, to accomplish one's goals" (Thompson, 1994, pp. 27-28). All strategies used to reduce, increase, or maintain positive or negative emotions are referred to as emotion regulation. Furthermore, being able to regulate emotions is associated with high levels of resilience. ArtuchGarde et al. (2017) exposed in their cross-sectional research that the ability to self-regulate behavior is associated with high levels of resilience in high-school students. Emotion research has demonstrated the importance of emotion regulation in adaptation, cognition, well-being, attention, and social interaction (f.i., Peña-Sarrionandia et al., 2015; Mayer et al., 2016). In fact, emotional dysregulation can undermine decisionmaking processes, increase anxiety, and produce a lack of social competence (Loewenstein and Lerner, 2003; Wills et al., 2016; Hartman et al., 2017). Lee et al. (2017) found out that emotion-focus coping strategy was also determinant enhancing a resilient outcome. Because stressful events have by nature an emotional component, people's ability to manage emotions may be another critical factor determining resilience (Caston \& Mauss, 2011)

Positive future orientation is the third indicator of resilience. Seginer (2008) argues that adolescents who develop resilience can better construct their future. Gartland et al. (2011) identified studies claiming that resilient adolescents are more likely to be optimistic, have a positive sense of the future, and hold future attainment objectives than those affected by stress. Boden et al. (2016) identified studies demonstrating the positive impact of resiliency on future aspirations. Wyman et al. (1993) found that children with high future expectations had less anxiety/depression, more self-reported competence, higher reading achievement scores and were rated by teachers as more engaged and better adjusted socio-emotionally. Students with higher levels of ambition and optimism who expressed a desire to obtain employment that enabled them to get ahead earned more money as adults than teenagers with less ambition and optimism (Ashby \& Schoon, 2010). In a study examining psychosocial resilience in rural adolescents, teens who had more positive expectations for their future were less negatively impacted when adverse events occurred and they displayed more active perseverance than those who expected worse outcomes (Tusaie, Puskar \& Sereika, 2007).

\section{Research Method}


The study employed a quantitative, non-experimental design of research using the descriptive correlational technique in which it is the most commonly employed approach in determining whether the independent and dependent has significant relationship using statistical data. Also, non-experimental quantitative research was utilized to determine the nature of a situation existing in this study. Likewise, non-experimental research was not generally directed toward hypothesis testing. Thus, this was an appropriate research design to use in the study to describe the relationship between the social support and personal resilience of government employees.

The study surveyed 210 government employees in Region XI. The researcher utilized simple random sampling in selecting the appropriate respondents. A purely random is a set of a numerical population in which each sub-set respondents has an equivalent chance of being selected. A simple random test is intended to represent a group in an unbiased manner (Hayes, 2019). The survey information is generally assumed to follow quantitative probability distribution, so all of the detail is found in the means and regression coefficients equation. Inclusion criteria include ability of government employees to read and write in the consent form and survey instrument, comprehend instruction and those who voluntarily submit to the test. Additionally, those who are willing to give consent and lastly, those who are willing to participate were included in the study. Meanwhile, exclusion criteria include those who are not willing to participate. Lastly, withdrawal criteria include violation of the researcher to the privacy of the respondents and confidentiality of their identity that needed to be protected. The respondents are free to make decisions not to engage, refuse to take part or terminate involvement at any time without any punishment or loss of any advantage to which they are anything else obligated. It shall also take into account the definition or clarification of the existence and probability of the potential distress or negative effects, including cognitive dangers, if any, and what has been done to mitigate such hazards, and the measures to be taken where appropriate.

The following numerical measures used in the computation of data and testing the hypotheses level significance of 0.05; the mean was used to determine the level of social support and personal resilience of government employees; the pearson $r$ was utilized to establish the significant relationship between social support and personal resilience of government employees; the linear regression was used to determine the significant influence of social support on the personal resilience of government employees.

\section{Results and Discussion}

Presented in Table 1 is the level of social support of government employees. The overall mean score 3.99, verbally described as high. The result shows that, as described, social support was oftentimes manifested. The standard deviation was less than 1.00, which signified the consistency of responses among the respondents. Scrutinizing the individual results of the level of social support of government employees on the following indicators were as follows: instrumental support has a mean of 4.20 labelled as very high and got the highest mean score among indicators, next is emotional support which has a mean of 4.05 with a descriptive level of high, high support seeking has a mean of 3.90 with descriptive equivalent of high and the lowest mean score is the need for support which has a mean of score of 3.81 with descriptive level of high.

Table 1. Level of Social Support of Government Employees

\begin{tabular}{|l|c|c|c|}
\hline \multicolumn{1}{|c|}{ Indicator } & SD & Mean & Descriptive Level \\
\hline Emotional Support & 0.62 & 4.05 & High \\
\hline $\begin{array}{l}\text { Instrumental } \\
\text { Support }\end{array}$ & 0.70 & 4.20 & Very High \\
\hline Need for Support & 0.63 & 3.81 & High \\
\hline Support Seeking & 0.68 & 3.90 & High \\
\hline \multicolumn{1}{|c|}{ Overall } & $\mathbf{0 . 5 4}$ & $\mathbf{3 . 9 9}$ & High \\
\hline
\end{tabular}

The high-level result of the social support of the government officials is parallel to the findings of Colarossi \& Eccles (2003) that social support affects mental health outcomes by increasing beliefs of acceptance, self-worth and connectedness to others. These findings also support the study of Osbay, et. al (2007), said 
that social support seems to moderate genetic and environmental vulnerabilities for mental illness, possibly by effects through other psychological factors, such as fostering effective coping strategies.

Reflected in Table 2 is the level of personal resilience of government employees. The overall mean score was 4.08, labelled as high. The high-level result means that personal resilience is oftentimes manifested. Data revealed that the indicators got the highest mean is positive future orientation which has a mean score of 4.57 with descriptive equivalent of very high, followed by emotional regulation which has a mean score of 4.02 with descriptive equivalent of high and the lowe3st mean score is novelty seeking which has a mean score of 3.67 with descriptive equivalent of high.

Table 2. Level of Personal Resilience of Government Employees

\begin{tabular}{|l|c|c|c|}
\hline \multicolumn{1}{|c|}{ Indicator } & SD & Mean & Descriptive Level \\
\hline Novelty Seeking & 0.51 & 3.67 & High \\
\hline $\begin{array}{l}\text { Emotional } \\
\text { Regulation }\end{array}$ & 0.52 & 4.02 & High \\
\hline $\begin{array}{l}\text { Positive Future } \\
\text { Orientation }\end{array}$ & 0.57 & 4.57 & Hery High \\
\hline \multicolumn{1}{|c|}{ Overall } & $\mathbf{0 . 4 3}$ & $\mathbf{4 . 0 8}$ & High \\
\hline
\end{tabular}

The high-level result of personal resilience is in consonance to the findings of Masten (2001) suggested that resilience stems from the healthy operation of basic human adaptational systems. Result of this study is also parallel to the findings of Gartland (2011) which claim that resilient people are more likely to be optimistic, have a positive sense of the future, and hold future attainment objectives than those who are not resilient. Shown in Table 3 is the significant relationship between the social support and personal resilience of government employees. Social support when correlated with the personal resilience, yielded an overall rvalue of .656 with p-value less than 0.05 . Therefore, the two variables are significantly related to each other. Thus, the null hypothesis of no significant relationship between social support and personal resilience of government employees was, therefore, rejected. Further, the indicators of social support correlated with indicators of personal resilience yielded the following results: emotional support correlated with novelty seeking, emotional regulation, and future orientation got an overall r-value of .567at p-value less than 0.05. Instrumental support correlated with novelty seeking, emotional regulation, and future orientation got an overall r-value of .530 with p-value less than 0.05 . Need for support correlated with novelty seeking, emotional regulation, and future orientation got an overall r-value of .539 with p-value less than 0.05. Support seeking correlated with novelty seeking, emotional regulation, and future orientation got an overall $\mathrm{r}$-value of .513 with p-value less than 0.05 . Therefore, all indicators of social support when correlated to all indicators of personal resilience are significant. Moreover, the indicators of personal resilience correlated with indicators of social support showed the following results: novelty seeking correlated with emotional support, instrumental support, need for support and support seeking obtained an overall r-value of.573 with p-value less than 0.05. Emotional regulation correlated with emotional support, instrumental support, need for support and support seeking obtained an overall r-value of .504 with p-value less than 0.05. Positive future orientation correlated with emotional support, instrumental support, need for support and support seeking obtained an overall r-value of .520 with p-value less than 0.05

Table 3. Significance on the Relationship between Social Support and Personal Resilience of Government Employees

\begin{tabular}{|c|c|c|c|c|}
\hline \multirow{2}{*}{ Social Support } & \multicolumn{4}{|c|}{ Personal Resilience } \\
\cline { 2 - 5 } & $\begin{array}{c}\text { Novelty } \\
\text { Seeking }\end{array}$ & $\begin{array}{c}\text { Emotional } \\
\text { Regulation }\end{array}$ & $\begin{array}{c}\text { Positive } \\
\text { Future } \\
\text { Orientation }\end{array}$ & Overall \\
\hline Emotional Support & $.423^{* *}$ & $.495^{* *}$ & $.460^{* *}$ & $\mathbf{. 5 6 7}^{* *}$ \\
& .000 & .000 & .000 & $\mathbf{. 0 0 0}$ \\
\hline
\end{tabular}




\begin{tabular}{|c|l|l|l|l|}
\hline Instrumental Support & $.391^{* *}$ & $.416^{* *}$ & $.477^{* *}$ & $\mathbf{. 5 3 0}^{* *}$ \\
& .000 & .000 & .000 & $\mathbf{. 0 0 0}$ \\
\hline Need for Support & $.549^{* *}$ & $.384^{* *}$ & $.383^{* *}$ & $\mathbf{. 5 3 9}^{* *}$ \\
& .000 & .000 & .000 & $\mathbf{. 0 0 0}$ \\
\hline Support Seeking & $.517^{* *}$ & $.358^{* *}$ & $.378^{* *}$ & $\mathbf{. 5 1 3}^{* *}$ \\
& .000 & .000 & .000 & $\mathbf{. 0 0 0}$ \\
\hline Overall & $\mathbf{. 5 7 3}^{* *}$ & $\mathbf{. 5 0 4}^{* *}$ & $\mathbf{. 5 2 0}^{* *}$ & $\mathbf{. 6 5 6}^{* *}$ \\
& $\mathbf{. 0 0 0}$ & $\mathbf{. 0 0 0}$ & $\mathbf{. 0 0 0}$ & $\mathbf{. 0 0 0}$ \\
\hline
\end{tabular}

The findings of the study revealed that there is a significant relationship between social support and personal resilience of government employees. The findings support the idea of Cicchette \& Toth (1998) that the level and degree of social support affects the level of resilience as a protective factor of individuals. On the other hand, the study is in consonance to that of Marques and Berry (2021) which offers an analytical resilience framework for examining and improving work life balance, supplemented with three mini-cases followed by work life balance and resilience analysis of the cases demonstrating the strength and benefits of the resilience framework.

Displayed in Table 4 is the significance on the influence of social support on the personal resilience of government employees. As shown in the table, the computed F-ratio is 41.788 with p-value less than 0.05 which indicates that social support significantly influences personal resilience of government employees. The computed $\mathrm{R}^{2}$ is .448 which indicates that 44.8 percent of social support of government employees was explained by emotional support, instrumental support, need for support and support seeking. This means that 55.2 percent of the variation can be attributed to other factors not covered in this study. Examining further, the data reveal that among the four domains of social support, only instrumental support does not significantly influence personal resilience, with beta value of .034 and p-value of .707. Furthermore, emotional support with beta value of .361 and p-value less than 0.05 , need support with beta value of .275 and p-value less than 0.05 and support seeking with beta value of .151 and p-value less than 0.05 are found to have significant influence on personal resilience. Finally, among the three domains that significantly influence the personal resilience, emotional support is considered as the best predictor.

Table 4. Significance on the Influence of Social Support on the Personal Resilience of Government Employees

\begin{tabular}{|l|c|c|c|c|c|}
\hline \multicolumn{5}{|c|}{ Personal Resilience } \\
\hline \multicolumn{1}{|c|}{ Social Support } & $B$ & $\beta$ & $t$ & Sig. \\
\hline Constant & & 1.885 & & 10.976 & .000 \\
\hline $\begin{array}{l}\text { Emotional } \\
\text { Support }\end{array}$ & .251 & .361 & 4.321 & .000 \\
\hline $\begin{array}{l}\text { Instrumental } \\
\text { Support }\end{array}$ & & .021 & .034 & .376 & .707 \\
\hline Need for Support & & .190 & .275 & 3.891 & .000 \\
\hline Support Seeking & & .096 & .151 & 2.054 & .041 \\
\hline $\mathrm{R}$ & .669 & & & & \\
\hline $\mathrm{R}$ & .448 & & & & \\
\hline \multicolumn{1}{c}{$\mathrm{R}$} & .437 & & & & \\
\hline $\mathrm{F}$ & 41.788 & & & & \\
\hline $\mathrm{P}$ & .000 & & & & \\
\hline
\end{tabular}

\section{Conclusion and Recommendation}

As can be seen from the findings of the study, conclusions are drawn and presented in this section. The findings of this study confirm the significant influence of social support on the personal resilience of government employees. Moreover, findings provide evidence that the results showed that social support and personal resilience among government employees teachers are very high, meaning they are often 
manifested. Consequently, it indicates that there is a significant relationship between social support and personal resilience. Furthermore, it was found that among the four domains of social support, it was the emotional support emerged to be the best predictor for personal resilience. The conclusion can be associated to the results of Colarossi \& Eccles, 2003 who found out that social support acts as a shield against the negative effects of stressful life events and thus negative effects on mental health. Hence, the level and degree of social support affects the level of resilience as a protective factor in individuals (Cicchetti \& Toth, 1998). On the other hand, Marques and Berry (2021) offer an analytical resilience framework for examining and improving work life balance, supplemented with three mini cases followed by work life balance and resilience analysis of the cases demonstrating the strength and benefits of the resilience framework.

Based on the foregoing findings and conclusions, a number of recommendations are offered. Since there is a high level of social support, it is recommended for them to have subjects focused on enhancing the social support of government employees to make it very high. The human resource department may design a program to increase the following: 1) whenever I am not feeling well, other people show me that they are fond of me; 2) when I am worried, there is someone who helps me; 3) I get along best without any outside help and 4) If I do not know how to handle a situation, I ask others what they would do. These are the items in the instrument that got the lowest mean in each domain of the social support. Likewise, there is a high level for personal resilience, the same recommendation is expressed. The following items are recommended to be the focused for inhouse training since these are the items in the questionnaire for personal resilience which got the lowest mean. Such as, 1) I find it bothersome to start new activities; 2) I think I have perseverance and 3) I have a clear goal for the future. The significant relationship and influence of social support to the personal resilience recommended that the policymakers, particularly the officials from the national government, review and revisit their existing policies if it addresses the demands and challenges in times of pandemic, mainly focusing on how to heighten employees' social support, hence, also improving their personal resilience.

Finally, future studies toward examining other variables that can possibly influence between personal resilience which will be of utmost importance to the research community shall be taken into consideration.

\section{References}

1. Artuch-Garde, R., González-Torres, M. D. C., de la Fuente, J., Vera, M. M., Fernández-Cabezas, M., and López-García, M. (2017). Relationship between resilience and self-regulation: a study of spanish youth at risk of social exclusion. Front. Psychol. 8:612. doi: 10.3389/fpsyg.2017.00612

2. Ashby, J., \& Schoon, I. (2010). The role of aspirations, ambition and gender in predicting adult social status and earnings. Journal of Vocational Behavior, 77(3), 350-360.

3. Bartlett, J. D \& Vivrette, R. (2020). Ways to Promote Children's Resilience to the COVID-19 Pandemic. $\quad$ https://www.childtrends.org/wpcontent/uploads/2020/04/COVIDProtectiveFactors_ChildTrends_April2020.pdf

4. Bermpohl, F. et al. (2007). Novelty seeking modulates medial prefrontal activity during the anticipation of emotional stimuli. Psychiatry Res. 164, 81-85, 10.1016/j.pscychresns.2007.12.019 (2008).

5. Black DW, Shaw M, McCormick B, Bayless JD, Allen J (2012) Neuropsychological performance, impulsivity, ADHD symptoms, and novelty seeking in compulsive buying disorder. Psychiatry Res 200:581-587, doi:10.1016/j.psychres.2012.06.003, pmid:22766012.C

6. Boden, J. M., Sanders, J., Munford, R., Liebenberg, L., \& McLeod, G. F. (2016). Paths to positive development: A model of outcomes in the New Zealand youth transitions study. Child Indicators Research, 9(4), 889-911

7. Brooks, S., Webster, R. S., Woodland, L., Wessely, S., Greenberg, N., et al. (2020). The psychological impact of quarantine and how to reduce it: rapid review of the evidence. Lancet 395:10227. doi: 10.1016/S0140-6736(20)30460-8

8. Burleson, B, R. (1990). Comforting as everyday social support: relational consequences of supportive behaviors. In S. duck with R silver Eds. Personal relationships and social support (pp. 6682). Loldon: sage publication 
9. Burleson, B. (2003). The experience and effects of emotional support: what the study of cultural and gender differences can tell us about close relationships, emotional and interpersonal communication. Personal relationships, 10(1), 1-23.

10. Caston, A. T., and Mauss, I. B. (2011). "Resilience in the face of stress: emotion regulation as a protective factor," in Resilience and Mental Health: Challenges Across the Lifespan, eds S. M. Southwick, B. T. Litz, D. Charney, and M. J. Friedman (New York City: Cambridge University Press), 30-44.

11. Catrona, E. and Russell, D. (1990). Types of social support and specific stress: toward a theory of optimal matching. In sarson, R., Sarason, G., \& Peirce, R. (Eds.), social support: an international view. New York: Wiley

12. Center for Developing Child. (2020). How to Help Families and Staff Build Resilience During the COVID-19 Outbreak. Harvard University.

13. Chassin L., Ritter J., Trim R.S., King K.M. Adolescent substance use disorders. Child Psychopathol. 2003;2:199-230.

14. Cicchetti, D., \& Toth, S. L. (1998). The development of depression in children and adolescents. American Psychologist, 53(2), 221-241. https://doi.org/10.1037/0003-066X.53.2.221

15. Cloninger, C. R., Przybeck, T. R. \& Svrakic, D. M. (1991). The Tridimensional Personality Questionnaire: U.S. normative data. Psychol. Rep. 69, 1047-1057, 10.2466/pr0.1991.69.3.1047 (1991).

16. Cluver, L., Lachman, J. M., Sherr, L., Wessels, I., Krug, E., Rakotomalala, S., Blight, S., Hillis, S., Bachman, G., Green, O., Butchart, A., Tomlinson, M., Ward, C. L., Doubt, J., \& McDonald, K. (2020). Parenting in a time of COVID-19. Lancet (London, England), 395(10231), e64. https://doi.org/10.1016/S0140-6736(20)30736-4q

17. Cohen, S. (2004). Social relationships and health. American psychologist, 59(8), 676- 684.

18. Cohen, S., \& Wills, T. A. (1985) Stress, social support, and the buffering hypothesis. Psychological Bulletin, 98, 310-357.

19. Colarossi, L. G., \& Eccles, J. S. (2003). Differential effects of support providers on adolescents' mental health. Social Work Research, 27(1), 19-30. https://doi.org/10.1093/swr/27.1.19

20. Connor, K. M., \& Davidson, J. R. T. (2003). Development of a New Resilience Scale: The ConnorDavidson Resilience Scale (CD-RISC). Depression and Anxiety, 18, 7682.http://dx.doi.org/10.1002/da.10113

21. Duclot, F. and Kabbaj, M. (2013). Individual Differences in Novelty Seeking Predict Subsequent Vulnerability to Social Defeat through a Differential Epigenetic Regulation of Brain-Derived Neurotropic Factor Expression. Journal of Neuroscience 3 July 2013, 33 (27) 11048-11060; DOI: https://doi.org/10.1523/JNEUROSCI.0199-13.2013

22. Dumont, M., \& Provost, M. A. (1999). Resilience in adolescents: Protective role of social support, coping strategies, self-esteem, and social activities on experience of stress and depression. Journal of Youth and Adolescence, 28(3), 343-363. https://doi.org/10.1023/A:1021637011732

23. Eley DS, Leung J, Hong BA, Cloninger KM, Cloninger C Robert (2016). Identifying the Dominant Personality Profiles in Medical Students: Implications for Their Well-Being and Resilience. PLoS ONE 11 (8): e0160028. doi:10.1371/journal.pone.0160028

24. Fingerman, K., Miller, L., Birditt, K., \& Zarit, S. (2009). Giving to the good and needy: Parental support of grown children. Journal of Marriage and Family, 71, 1220- 1233.

25. Gartland, D., Bond, L., Olsson, C. A., Buzwell, S., \& Sawyer, S. M. (2011). Development of a multidimensional measure of resilience in adolescents: The Adolescent Resilience Questionnaire. BMC Medical Research Methodology, 11(1), 134.

26. Gregory R. Pierce, Barbara R. Sarason, and I Rwin G. Sarason (1996). Handbook of social support and the family. Springer science business media New York: plenum press

27. Hartman S. D., Wasieleski D. T., Whatley M. A. (2017). Just breathe: the effects of emotional dysregulation and test anxiety on GPA. Coll. Stud. J. 51, 142-151.

28. Heaney CA, Israel BA. (2002) .Social networks and social support. Health Behav and Health Educ: Theory, Res, and Practice. 2002;3:185-209.

29. Jew, C. L., Green, K. E., \& Kroger, J. (1999). Development and validation of a measure of resiliency. Measurement and Evaluation in Counseling and Development, 32(2), 75-89. 
30. Johnson, C.P., \& Kastner, T. A. (2005). Helping families raise children with special health care needs at home. Pediatrics, 115, 507-511

31. Josefsson K, Merjonen P, Jokela M, Pulkki-Råback L, Keltikangas-Järvinen L (2011) Personality profiles identify depressive symptoms over ten years? A population-based study. Depress Res Treat 2011:431314, doi:10.1155/2011/431314, pmid:21876796.

32. Kim, S., \& Esquivel, G. B. (2011). Adolescent spirituality and resilience: Theory, research, and educational practices. Psychology in the Schools, 48(7), 755-765. doi:10.1002/pits.20582.

33. Lee, J. H., Seo, M., Lee, M., Park, S. Y., Lee, J. H., and Lee, S. M. (2017). Profiles of coping strategies in resilient adolescents. Psychol. Rep. 120, 49-69. doi: 10.1177/0033294116677947

34. Loewenstein G. F., Lerner J. S. (2003). The role of affect in decision making, in Handbook of Affective Science, eds Goldsmith R., Davidson H., Scherer K. (Madrid: Oxford University Press), 619-642.

35. Malecki CK, \& Demaray MK (2003). What types of support do they need? Investigating student adjustment as related to emotional, informational, appraisal, and instrumental support. School Psychology Quarterly, 18, 231-252.

36. Marques V., Berry G., (2021). Enhancing Work Life Balance Using a Resilience Framework. Wiley Online Library. Business and Society Review.

37. Masten, A.S. (2015). Ordinary magic: resilience in development. Guilford Publications

38. Masten, A. S., Best, K. M., \& Garmezy, N. (1990). Resilience and development: Contributions from the study of children who overcome adversity. Development and Psychopathology, 2(4), 425444. https://doi.org/10.1017/S0954579400005812

39. Mayer J. D., Caruso D. R., Salovey P. (2016). Seven principles of emotional intelligence the ability model of emotional intelligence: principles and updates. Emot. Rev. 8, 290-300.

40. Miller G.E., Lachman M.E., Chen E., Gruenewald T.L., Karlamangla A.S., Seeman T.E. (2011). Pathways to resilience: maternal nurturance as a buffer against the effects of childhood poverty on metabolic syndrome at midlife Psychol Sci. 2011 Dec; 22(12):1591-9

41. Miller, W. \& Rollnick, S. (2002). Motivational interviewing: Preparing people for change, $2 \mathrm{nd}$ Edition. New York, NY: Guilford Press. Misconceptions. Annu. Rev. Clin., 1, 31-65

42. Naghavi, H. R., Lind, J., Nilsson, L. G., Adolfsson, R. \& Nyberg, L.(2008). Personality traits predict response to novel and familiar stimuli in the hippocampal region. Psychiatry Res 173, 94-99, 10.1016/j.pscychresns.2008.09.011 (2009).

43. Ozbay, F., (2007). Social Support and Resilience to Change. From Neurobiology to Clinical Practice. Psychiatry Matrix Medical Communications.

44. Parker, K. and Rainwater, C. (2007). Early life stress and novelty seeking behavior in adolescent monkeys. Psychoneuroendocrinology 32(7):785-92 DOI: 10.1016/j.psyneuen.2007.05.008

45. Peña-Sarrionandia A., Mikolajczak M., Gross J. J. (2015). Integrating emotion regulation and emotional intelligence traditions: a meta-analysis. Front. Psychol. 6:160. 10.3389/fpsyg.2015.00160 perspectives (pp. 97-142). Greenwich, CO: JAI Press Inc.

46. Pierce, G. Sarason, I. \& Sarason, B. (1990). Integrating social support perspectives: working models, personal relationships, and situational factors. In S. duck with R.silver (Eds.), personal relationships and social support(pp. 173-189). London: sage publications.

47. Reblin, M., \& Uchino, B. N. (2008). Social and emotional support and its implication for health. Current opinion in psychiatry, 21(2), 201-205. https://doi.org/10.1097/YCO.0b013e3282f3ad89

48. Rome ES, Dinardo PB, Issac VE. Promoting resiliency in adolescents during a pandemic: A guide for clinicians and parents. Cleve Clin J Med. 2020 Oct 1;87(10):613-618. doi: 10.3949/ccjm.87a.20055. PMID: 33004322.

49. Russek L.G., Schwartz G.E., and Behav, J.(1997). Feelings of parental caring predict health status in midlife: a 35-year follow-up of the Harvard Mastery of Stress Study.

50. Rutter, M. \& Madge, N. (1976). Cycles of disadvantage: A review of research. London: Heinemann.

51. Rutter, M. (1987). Developmental psychiatry (1st American Psychiatric Press ed.). Washington, DC: American Psychiatric Press.

52. Rutter, M. (1987). Psychosocial resilience and protective mechanisms. American Journal of Orthopsychiatry, 57(3), 316-331. 
53. SAMHSA Disaster Line (2020). Resilience and Stress Management Resource Collection. Assistant Secretary for Preparedness and Response (ASPR), 200 Independence Avenue S.W., Washington, D.C., 2020

54. Seginer, R. (2008). Future orientation in times of threat and challenge: How resilient adolescents construct their future. International Journal of Behavioral Development, 32(4), 272-282.

55. Thompson R. A. (1994). Emotion regulation: a theme in search of definition. Monogr. Soc. Res. Child Dev. 59, 25-52. 10.2307/1166137

56. Tso, W.W.Y., Wong, R.S., Tung, K.T.S. et al. Vulnerability and resilience in children during the COVID-19 pandemic. Eur Child Adolesc Psychiatry (2020). https://doi.org/10.1007/s00787-020$\underline{01680-8}$

57. Tusaie, K., Puskar, K., \& Sereika, S. M. (2007). A predictive and moderating model of psychosocial resilience in adolescents. Journal of Nursing Scholarship, 39(1), 54- 60.

58. Wagnild, G. M., \& Young, H. M. (1993). Development and psychometric evaluation of the Resilience Scale. Journal of Nursing Measurement, 1(2), 165-178.

59. Werner, E. (1982). Vulnerable but invincible: A longitudinal study of resilient children and youth. New York: McGraw-Hill

60. Werner, E. E. (1995). Resilience in development. Current Directions in Psychological Science, 4(3), 81-85. https://doi.org/10.1111/1467-8721.ep10772327

61. Westerlund H., Gustafsson P.E., Theorell T., Janlert U., Hammarström A.,Epidemiol, J. (2013). Parental academic involvement in adolescence, academic achievement over the life course and allostatic load in middle age: a prospective population-based cohort study. Community Health. 2013 Jun; 67(6):508-13.

62. Wills T. A., Simons J. S., Sussman S., Knight R. (2016). Emotional self-control and dysregulation: a dual-process analysis of pathways to externalizing/internalizing symptomatology and positive wellbeing in younger adolescents. Drug Alcohol Depend. 163, S37-S45. 10.1016/j.drugalcdep.2015.08.03

63. Wittmann, B. C., Daw, N. D., Seymour, B. \& Dolan, R. J. (2008). Striatal activity underlies noveltybased choice in humans. Neuron 58, 967-973, 10.1016/j.neuron.2008.04.027 (2008).

64. Wu PJ, Chang SM, Lu MK, Chen WJ, Yang YK, Yeh TL, Liao SC, Lu RB, Kuo PH (2012). The profile and familiality of personality traits in mood disorder families. J Affect Disord 138:367-374, doi:10.1016/j.jad.2012.01.015, pmid:22331025.

65. Wyman, P. A., Cowen, E. L., Work, W. C., \& Kerley, J. H. (1993). The role of children's future expectations in self-system functioning and adjustment to life stress: A prospective study of urban atrisk children. Development and Psychopathology, 5(4), 649-661.

66. Xiao, H., Zhang, Y., Kong, D., Li, S., and Yang, N. (2020). The effects of social support on sleep quality of medical staff treating patients with coronavirus disease 2019 (COVID-19) in January and February 2020 in China. Med. Sci. Monit. 26:e923549. doi: 10.12659/MSM.923549 